\title{
Prevalence and risk factors of airflow obstruction in an elderly Chinese population
}

\author{
F.W.S. Ko*, J. Woo", W. Tam, C.K.W. Lai*, J. Ngai*, T. Kwok" and D.S.C. Hui*
}

ABSTRACT: It is common practice to use a forced expiratory volume in one second (FEV 1$) /$ forced vital capacity (FVC) ratio of $<70 \%$ as evidence of airflow obstruction. As the FEV $1 / F V C$ ratio falls with age, the lower limit of normal range (LLN), defined as the bottom $5 \%$ in a health reference population, of FEV1/FVC ratio has been suggested as a better index to reduce over-diagnosis of chronic obstructive pulmonary disease (COPD), particularly in the elderly. However, there are no large scale studies that focus on the diagnosis of COPD in the elderly based on these definitions. The present prospective epidemiological study involved 1,149 elderly subjects aged $\geqslant 60$ yrs in the community. Detailed questionnaires, pre- and post-bronchodilator spirometry were performed.

In total, 1,008 subjects (mean age $74.2 \pm 6.4$ yrs; 271 males) completed satisfactory spirometry testing. Airflow obstruction was present in $25.9 \%$ as defined by the post-bronchodilator FEV $1 / F V C$ ratio of $<70 \%$ and in $\mathbf{1 2 . 4 \%}$ defined by the LLN of FEV $1 / F V C$ ratio. Moderate COPD, at least, was found in $\mathbf{1 4 . 0} \%$ of patients according to the post-bronchodilator $\mathrm{FEV}_{1} / \mathrm{FVC}$ ratio of $<70 \%$ and in $8.5 \%$ of patients according to LLN of FEV $1 / F V C$ ratio.

In the present elderly Chinese population (mostly females, with low education level and previous exposure to biomass during formative years), the prevalence of chronic obstructive pulmonary disease varied markedly depending on definitions adopted. Further longitudinal studies are needed to determine the precise definition of chronic obstructive pulmonary disease.

\section{KEYWORDS: Airflow obstruction, chronic obstructive lung disease, elderly, lung function}

hronic obstructive pulmonary disease (COPD) was the fifth leading cause of death worldwide in 2001 and it has been predicted by the World Health Organization to rank the third by 2020 [1, 2]. A previous study, based on respiratory symptoms, estimated the prevalence of COPD among the elderly Chinese (aged $\geqslant 70$ yrs) living in the Hong Kong as 9\% [3]. Objective studies with lung function tests are required for a more accurate estimation of the prevalence of COPD in Hong Kong community.

The Global Initiative for Chronic Obstructive Lung Disease (GOLD) guidelines currently recommend a fixed spirometric ratio of forced expiratory volume in one second (FEV1)/ forced vital capacity (FVC) of $<70 \%$ for the diagnosis of COPD [4]. However, there are controversies over this simple definition, particularly in the elderly population as the FEV1/FVC ratio falls with age [5-8], therefore, using this definition may result in over-diagnosis of COPD. An alternative way of defining airflow obstruction by is using the lower limit of normal range (LLN) values for the FEV1/FVC ratio, which are based on normal distribution and classify the bottom $5 \%$ of the healthy population as abnormal $[9,10]$. This approach has been suggested by the GOLD guidelines as one way to minimise the potential misclassification of COPD [4].

There are currently no large-scale studies focusing on the elderly population (aged $>60 \mathrm{yrs}$ ) that compare the FEV1/FVC fixed ratio of $<70 \%$ with the LLN of the FEV1/FVC ratio for the assessment of airflow obstruction. The aim of the present study was to assess the prevalence of airflow obstructions in elderly subjects living in the Hong Kong community using these two different definitions. In addition, the agreement of airflow obstructions using the different definitions was compared and their relationships with the symptoms and risk factors of the subjects were assessed.

\section{METHODS}

The present prospective epidemiological study recruited subjects from community centres in

\section{AFFILIATIONS}

Depts of *Medicine and

Therapeutics,

\#Community and Family Medicine, and

'Nethersole School of Nursing, The Chinese University of Hong Kong,

Shatin, Hong Kong.

CORRESPONDENCE

D.S.C. Hui

Dept of Medicine and Therapeutics The Chinese University of Hong Kong Prince of Wales Hospital 30-32 Ngan Shing Street Shatin

New Territories

Hong Kong

Fax: 85226489957

E-mail: dschui@cuhk.edu.hk

Received:

April 182008

Accepted after revision:

July 192008

SUPPORT STATEMENT

The present study was supported by the Hong Kong Lung Foundation Research Grant (Kowloon, Hong Kong) and the Respiratory Research Fund of the Chinese University of Hong Kong (Shatin, Hong Kong).

STATEMENT OF INTEREST

None declared. 
Hong Kong where senior citizens attended social gatherings. Community centres were selected randomly for participation in the study and each centre put up a poster to advertise the present study to the elderly people during their group activities. Elderly subjects aged $\geqslant 60$ yrs who were willing to join the study were requested to attend each centre on designated days for testing. Informed written consent was obtained from each subject and the study was approved by the research ethics committee of the Chinese University of Hong Kong (Shatin, Hong Kong).

During the day of testing, a doctor and three research assistants attended the centre. A questionnaire based on the American Thoracic Society (ATS) questionnaire for chronic respiratory symptoms [11] was administered by face-to-face interview. The interviewer read the Chinese version of the questions to the elderly participants and recorded the answers for them. Data regarding their respiratory symptoms, sex, age, smoking status, education level, exposure to biomass, etc., were obtained.

Both cough and sputum production were defined as having the respective symptoms for $\geqslant 3$ months in the previous year. Wheeze was defined as having at least one episode of a whistling noise in the chest in the previous 12 months. Dyspnoea was defined as having shortness of breath while walking on level ground or slightly uphill at normal speed. Passive smoking was defined as exposure to passive smoke either at work or at home regularly for $\geqslant 5$ yrs. Biomass exposure was defined as exposure to biomass for a period of $\geqslant 10$ yrs (firewood, grass, kerosene or coal on average for $>3 \mathrm{~h}$ per day).

The height and weight of the subjects was measured with the subjects wearing indoor clothing without shoes [12, 13]. Spirometry was performed using the MICROLAB 3300 spirometer (Micro Medical, Kent, UK) in a sitting position, according to the ATS/European Respiratory Society (ERS) standards [14]. The subjects were instructed to perform a minimum of three (and a maximum of eight) blowing manoeuvres. Both pre- and post-bronchodilator tests were performed (20 min after inhaling $400 \mu \mathrm{g}$ of salbultamol through a $500 \mathrm{~mL}$ spacer (Ventolin; GlaxoSmithKline, Évreux, France)). The updated predicted spirometric (FEV1, FVC and LLN of the FEV1/FVC ratio) values for the Hong Kong Chinese were used [12]. All the spirometry results were screened by the respiratory physicians (F.W.S. Ko and J. Ngai) and only results which met the ATS/ERS standards were included in the analysis [14].

COPD was defined by lung function as follows: 1) an obstructive lung function with post-bronchodilator FEV1/ FVC ratio of $<70 \%$ as defined by the GOLD guidelines [4]; or 2) using the LLN, as defined by the lowest 5 th percentile in the population $[9,10]$, using the following equations derived from a recent population study in Hong Kong [12].

LLN of FEV1/FVC ratio for males is:

$$
\begin{gathered}
0.00932+\left(1.409 \times 10^{-5}\right) \times \text { age }+\left(-3.038 \times 10^{-7}\right) \times \text { age }^{2}+ \\
\left(-4.001 \times 10^{-5}\right) \times \text { height }
\end{gathered}
$$

LLN of FEV1/FVC ratio for females is:

$$
\begin{gathered}
0.01119+\left(-1.062 \times 10^{-5}\right) \times \text { age }+\left(-2.046 \times 10^{-8}\right) \times \text { age }^{2}+ \\
\left(-4.900 \times 10^{-5}\right) \times \text { height }
\end{gathered}
$$

\begin{tabular}{|c|c|c|c|}
\hline \multirow[t]{2}{*}{ TABLE 1} & \multirow[b]{2}{*}{ Male } & \multirow[b]{2}{*}{ Female } & \multirow[t]{2}{*}{$\begin{array}{l}\text { who } \\
\text { tion }\end{array}$} \\
\hline & & & \\
\hline Subjects $n$ & 271 & 737 & 1008 \\
\hline Age yrs & $74.7 \pm 6.0$ & $74.1 \pm 6.6$ & $74.2 \pm 6.4$ \\
\hline \multicolumn{4}{|l|}{ Smoking status } \\
\hline Nonsmoker & $105(38.7)$ & $650(88.2)$ & $755(74.9)$ \\
\hline Ex-smoker & $137(50.6)$ & $71(9.6)$ & $208(20.6)$ \\
\hline Current smoker & $29(10.7)$ & $16(2.1)$ & $45(4.5)$ \\
\hline BMI $\mathbf{k g} \cdot \mathrm{m}^{-2}$ & $23.8 \pm 3.3$ & $24.2 \pm 4.6$ & $24.1 \pm 4.3$ \\
\hline \multicolumn{4}{|l|}{ Years of education } \\
\hline Not completed primary school & $72(26.6)$ & $468(63.5)$ & $540(53.6)$ \\
\hline Completed primary school & $109(40.7)$ & $185(25.1)$ & $295(29.1)$ \\
\hline Completed secondary school & $66(24.6)$ & 71 (9.6) & $137(13.6)$ \\
\hline Tertiary education or above & $24(9.0)$ & $13(1.8)$ & $37(3.7)$ \\
\hline \multicolumn{4}{|l|}{ IIIness history } \\
\hline TB & $30(11.1)$ & $43(5.8)$ & $73(7.2)$ \\
\hline COPD & $19(7.0)$ & $17(2.3)$ & $36(3.6)$ \\
\hline Asthma (current) & $13(4.8)$ & $29(3.9)$ & $42(4.2)$ \\
\hline Asthma (childhood, not current) & $1(0.4)$ & $27(3.7)$ & $28(2.8)$ \\
\hline Allergic rhinitis & $84(31.0)$ & 193(26.2) & $277(27.5)$ \\
\hline Atopy ${ }^{\#}$ by skin test & 99 (40.6) & $252(37.3)$ & $351(38.2)$ \\
\hline Subjects $n$ & 244 & 676 & 920 \\
\hline Passive smoking exposure & $117(43.2)$ & $353(47.9)$ & $470(46.6)$ \\
\hline \multicolumn{4}{|l|}{ Biomass exposure } \\
\hline Wood grass & $147(54.2)$ & $535(72.6)$ & $682(67.7)$ \\
\hline Average years of exposure & $13.8 \pm 9.3$ & $18.5 \pm 11.6$ & $17.5 \pm 11.3$ \\
\hline Kerosene & $175(64.6)$ & $585(79.4)$ & $760(75.4)$ \\
\hline Average years of exposure & $10.8 \pm 8.4$ & $11.3 \pm 7.4$ & $11.2 \pm 7.7$ \\
\hline Charcoal & $16(5.9)$ & $94(12.8)$ & $110(10.9)$ \\
\hline Average years of exposure & $7.3 \pm 8.7$ & $6.8 \pm 7.6$ & $6.9 \pm 7.7$ \\
\hline Coal & $6(2.2)$ & $23(3.1)$ & $29(2.9)$ \\
\hline Average years of exposure & $17.6 \pm 16.5$ & $12.7 \pm 10.3$ & $13.5 \pm 11.4$ \\
\hline $\begin{array}{l}\text { Any one of the above for } \\
\geqslant 10 \mathrm{yrs}\end{array}$ & $151(55.7)$ & $559(75.8)$ & $710(70.4)$ \\
\hline \multicolumn{4}{|l|}{ Respiratory symptoms } \\
\hline Cough $>3$ months & $32(11.8)$ & $66(9.0)$ & $98(9.7)$ \\
\hline Sputum $>3$ months & $60(22.1)$ & $82(11.1)$ & $142(14.1)$ \\
\hline Wheeze ever & $32(11.8)$ & $51(6.9)$ & $83(8.2)$ \\
\hline Dyspnoea on exertion & $81(29.9)$ & $232(31.5)$ & $313(31.0)$ \\
\hline \multicolumn{4}{|l|}{ Pre-bronchodilator } \\
\hline FEV 1 L & $1.8 \pm 0.5$ & $1.3 \pm 0.4$ & $1.4 \pm 0.5$ \\
\hline FVC L & $2.5 \pm 0.6$ & $1.7 \pm 0.5$ & $1.9 \pm 0.6$ \\
\hline \multicolumn{4}{|l|}{ Post-bronchodilator } \\
\hline FEV 1 L & $1.9 \pm 0.5$ & $1.3 \pm 0.4$ & $1.5 \pm 0.5$ \\
\hline FVC L & $2.6 \pm 0.6$ & $1.8 \pm 0.5$ & $2.0 \pm 0.6$ \\
\hline $\mathrm{FEV}_{1 / / F V C}$ ratio \% & $72.7 \pm 10.4$ & $77.0 \pm 10.7$ & $75.9 \pm 10.8$ \\
\hline FEV $1 \%$ pred & $85.3 \pm 20.6$ & $87.4 \pm 20.0$ & $86.8 \pm 20.2$ \\
\hline FVC \% pred & $85.6 \pm 17.7$ & $83.5 \pm 19.2$ & $84.1 \pm 18.8$ \\
\hline
\end{tabular}

Age was measured in years and height in metres.
Data are presented as $n(\%)$ or mean $\pm \mathrm{SD}$, unless otherwise stated. BMI: body mass index; TB: tuberculosis; COPD: chronic obstructive pulmonary disease; FEV1: forced expiratory volume in one second; FVC: forced vital capacity; $\%$ pred: \% predicted. ${ }^{\#}: \mathrm{n}=920 ; "$ : in the past year when free of infection. 
TABLE 2 Post-bronchodilator spirometry results by age

\begin{tabular}{|c|c|c|c|c|c|c|c|c|c|c|}
\hline \multirow{2}{*}{$\begin{array}{c}\text { Age } \\
\text { yrs }\end{array}$} & \multirow[t]{2}{*}{ Sex } & \multicolumn{3}{|c|}{ All subjects ${ }^{\#}$} & \multicolumn{3}{|c|}{ Current smokers and ex-smokers } & \multicolumn{3}{|c|}{ Nonsmokers $^{+}$} \\
\hline & & Subjects $n$ & $\begin{array}{c}\text { FEV }_{1} / \mathrm{FVC} \\
<0.7\end{array}$ & $\begin{array}{l}\text { LLN of } \\
\text { FEV } 1 / F V C^{-}\end{array}$ & Subjects $n$ & $\begin{array}{c}\text { FEV } 1 / F V C \\
<0.7\end{array}$ & $\begin{array}{c}\text { LLN of } \\
\text { FEV1/FVC }\end{array}$ & Subjects $n$ & $\begin{array}{c}\text { FEV } 1 / F V C \\
<0.7\end{array}$ & $\begin{array}{l}\text { LLN of } \\
\text { FEV1/FVC }\end{array}$ \\
\hline \multirow[t]{2}{*}{$60-69$} & Male & 43 & $11(25.6)$ & $6(14.0)$ & 20 & $7(35.0)$ & $5(25.0)$ & 23 & $4(17.4)$ & $1(4.3)$ \\
\hline & Female & 200 & $33(16.5)$ & $25(12.5)$ & 22 & $5(22.7)$ & $3(13.6)$ & 178 & $28(15.7)$ & $22(12.4)$ \\
\hline \multirow{2}{*}{$70-79$} & Female & 367 & $81(22.1)$ & $54(14.7)$ & 42 & $12(28.6)$ & $11(26.2)$ & 325 & $69(21.2)$ & $43(13.2)$ \\
\hline & All & 549 & $139(25.3)$ & $68(12.4)$ & 157 & $53(33.8)$ & $20(12.7)$ & 392 & $86(21.9)$ & $48(12.2)$ \\
\hline \multirow[t]{3}{*}{$\geqslant 80$} & Male & 46 & $20(43.5)$ & $2(4.3)$ & 31 & $19(61.3)$ & $2(6.5)$ & 15 & $1(6.7)$ & $0(0)$ \\
\hline & Female & 170 & $58(34.1)$ & $24(14.1)$ & 23 & $5(21.7)$ & $4(17.4)$ & 147 & $53(36.1)$ & 20 (13.6) \\
\hline & All & 216 & 78 (36.1) & 26 (12.0) & 54 & $24(44.4)$ & $6(11.1)$ & 162 & 54 (33.3) & 20 (12.3) \\
\hline All & Male & 271 & 89 (32.8) & $22(8.1)$ & 166 & $67(40.4)$ & $16(9.6)$ & 105 & 22 (21.0) & $6(5.7)$ \\
\hline
\end{tabular}

Data are presented as $n(\%)$, unless otherwise stated. FEV1: forced expiratory volume in one second; FVC: forced vital capacity; LLN: lower limit of normal range. \#: $n=1,008 ; \bullet: n=253 ;{ }^{+}: n=755$.

\section{Statistical analysis}

Based on a previous questionnaire, which estimated the prevalence rate of COPD as $9 \%$ in the Hong Kong community [3], with an assumption that using the FEV1/FVC ratio would diagnose 3\% more COPD cases than using the LLN of the FEV1/FVC ratio, a sample size of 923 could achieve $85 \%$ power to detect such a difference using a two-sided binomial test.

Data are presented as mean \pm SD and a p-value of $<0.05$ was considered as significant. The $\kappa$ coefficient was used to describe agreement between the different methods to define COPD. Univariate logistic regression analysis was conducted for each symptom/risk factor, crude odds ratio (OR) and confidence intervals (CIs) were computed. Those factors with a $\mathrm{p}$-value $<0.1$ in the univariate analyses were selected for the multivariate logistic regression analyses.

\section{RESULTS}

All the 20 elderly community centres approached participated in the present study. In total, 1,149 (296 males) subjects agreed to return to the centre on designated dates for assessment. All subjects completed the respiratory questionnaire and attempted the spirometry measurement. However, only 1,008 $(87.7 \%)$ subjects were able to perform the spirometry according to the ATS/ERS standards (with satisfactory spirometry tracings and reproducibility). The reasons for exclusion included inability to obtain three acceptable spirograms due to cough, premature termination of exhalation, variable effort or leakage, and inability to obtain two reproducible tests.

The demographic data of the subjects who had completed the lung function assessment are shown in table 1. All the subjects were aged $\geqslant 60$ yrs. The mean \pm SD smoking history for the exsmokers and current smokers were $21.9 \pm 24.3$ and $28.4 \pm 23.5$ pack-yrs, respectively.

The numbers and percentages of the subjects with airflow obstructions, as defined by the post-bronchodilator FEV1/FVC ratio of $<70 \%$ and LLN of the FEV1/FVC ratio, are shown in table 2 . The mean \pm SD forced expiratory time of the subjects for the post-bronchodilator FVC was $10.1 \pm 3.0 \mathrm{~s}$. The percentages of subjects with airflow obstruction was $25.9 \%$ (as defined by the post-bronchodilator FEV1/FVC ratio of $<70 \%$ ) versus $12.4 \%$ (as defined by the LLN of the FEV1/FVC ratio). The difference between the two definitions was more marked in older individuals (5.3 versus $16.1 \%$ difference in those $<70$ and $\geqslant 70$ yrs, respectively). In the subjects who had completed the spirometry examination, $158(15.7 \%)$ had demonstrated significant bronchodilator reversibility (FEV1 increased by $>0.2 \mathrm{~L}$ and $>12 \%$ post-bronchodilator). Table 3 shows the prevalence of the different severities of COPD using the FEV1 \% predicted values for both definitions of COPD.

The agreement between the different definitions of COPD is shown in table 4 . There was a moderate degree of agreement between the GOLD definition (post-bronchodilator FEV1/FVC fixed ratio of $<70 \%$ ) and both the pre- and post-bronchodilator LLN of the FEV1/FVC ratio ( $\kappa$ values ranged $0.42-0.58$; all $\mathrm{p}-$ values $<0.001$ ). However, both post-bronchodilator FEV1/FVC ratio and LLN of the FEV1/FVC ratio did not agree well with doctor-diagnosised of COPD, with $\kappa$ values of 0.06 and 0.05 , respectively. In fact, only 6.9 and $6.4 \%$ of the subjects with a FEV1/FVC ratio of $<70 \%$ and LLN of the FEV1/FVC ratio, respectively, had doctor-diagnosed COPD.

Logistic regression analyses were performed to assess the relationship between the symptoms of the subjects, together with their sex, education, body mass index (BMI), smoking status (both active and passive smoking), biomass exposure, and doctor-diagnosed COPD. Those factors with a statistically significant relationship with airflow obstructions are presented in table 5. For the univariate analysis, if the exposure to firewood for $\geqslant 10$ yrs was analysed separately from exposure to all biomasses, then exposure to firewood was associated with a LLN of the FEV1/FVC ratio (OR 1.69, 95\% CI 1.14-2.49; 
TABLE 3 The post-bronchodilator severity of chronic obstructive pulmonary disease (COPD) by different definitions

\begin{tabular}{|c|c|c|c|c|c|c|}
\hline \multirow[t]{2}{*}{ COPD severity } & \multicolumn{3}{|c|}{$\mathrm{FEV}_{1 / \mathrm{FVC}}$ ratio of $<\mathbf{7 0} \%$} & \multicolumn{3}{|c|}{ LLN of FEV $1 / F V C$ ratio } \\
\hline & Male & Female & All & Male & Female & All \\
\hline \multicolumn{7}{|l|}{ Mild } \\
\hline FEV $1>80 \%$ pred & 36 (40.5) & $84(48.8)$ & $120(46.0)$ & $0(0)$ & 39 (37.9) & $39(31.2)$ \\
\hline \multicolumn{7}{|l|}{ Moderate } \\
\hline $30 \% \leqslant$ FEV $1<50 \%$ pred & $8(9.0)$ & $17(9.9)$ & $25(9.6)$ & $6(27.3)$ & $15(14.6)$ & $21(16.8)$ \\
\hline \multicolumn{7}{|l|}{ Very Severe } \\
\hline $\mathrm{FEV}_{1}<30 \%$ pred & $1(1.1)$ & $1(0.6)$ & $2(0.7)$ & $1(4.5)$ & $0(0)$ & $1(0.8)$ \\
\hline Total COPD subjects & 89 & 172 & 261 & 22 & 103 & 125 \\
\hline
\end{tabular}

Data are presented as $\mathrm{n}(\%)$ or $\mathrm{n}$. FEV1: forced expiratory volume in one second; FVC: forced vital capacity; LLN: lower limit of normal range; \% pred: \% predicted.

$\mathrm{p}=0.008)$, but not with the FEV1/FVC fixed ratio of $<70 \%$ (OR $1.04,95 \%$ CI $0.79-1.38 ; \mathrm{p}=0.77)$. If all the biomass exposures were pooled together (i.e. exposure to combustion of wood, grass, kerosene, charcoal or coal for $\geqslant 10 \mathrm{yrs}$ ), then biomass exposure had no association with airflow obstruction in using the definition of FEV1/FVC ratio of $<70 \%$ (OR $0.93,95 \%$ CI $0.69-1.27$ ) or the LLN ratio of FEV1/FVC (OR 1.53, 95\% CI 0.98-2.38). Multivariate regression analysis showed that the diagnosis of COPD based on post-bronchodilator the FEV1/ FVC fixed ratio of $<70 \%$ had positive association with the symptom of exertional dyspnoea whereas LLN of the FEV1/ FVC ratio was associated with both the symptoms of wheeze and exertional dyspnoea.

\section{DISCUSSION}

To the best of the present authors' knowledge, this is the first major study that has focused specifically on elderly subjects, comparing the definition of post-bronchodilator FEV1/FVC fixed ratio of $<70 \%$ with the LLN of the FEV1/FVC ratio in assessing the prevalence of COPD. The current study is also the first to compare the two definitions in a non-Caucasian population. An enormous difference has been noted in the prevalence rates of COPD based on the different definitions (overall difference was $13.5 \%$ ). The fixed FEV1/FVC ratio of $<70 \%$ was introduced with the GOLD guidelines [4] to facilitate the definition of airflow obstruction especially in the countries where reference values for lung function tests were

TABLE 4 Agreement between various definitions of chronic obstructive pulmonary disease (COPD)

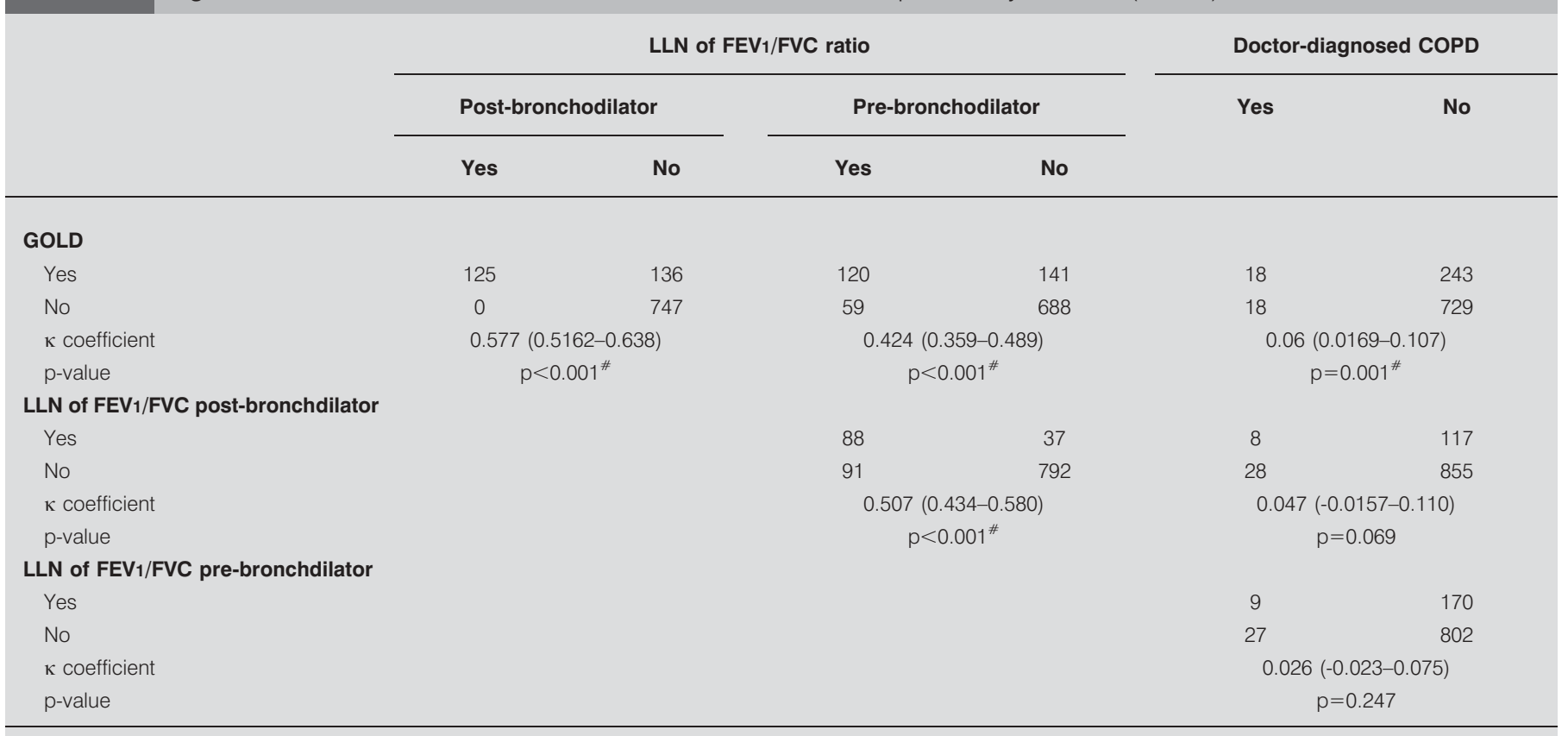

Data are presented as $\mathrm{n}$ or $\kappa$ coefficient (95\% confidence interval), unless otherwise stated. LLN: lower limit of normal range; FEV1: forced expiratory volume in one second; FVC: forced vital capacity; GOLD: Global Initiative for Chronic Obstructive Lung Disease. ${ }^{\#}: \mathrm{p}<0.05$. 


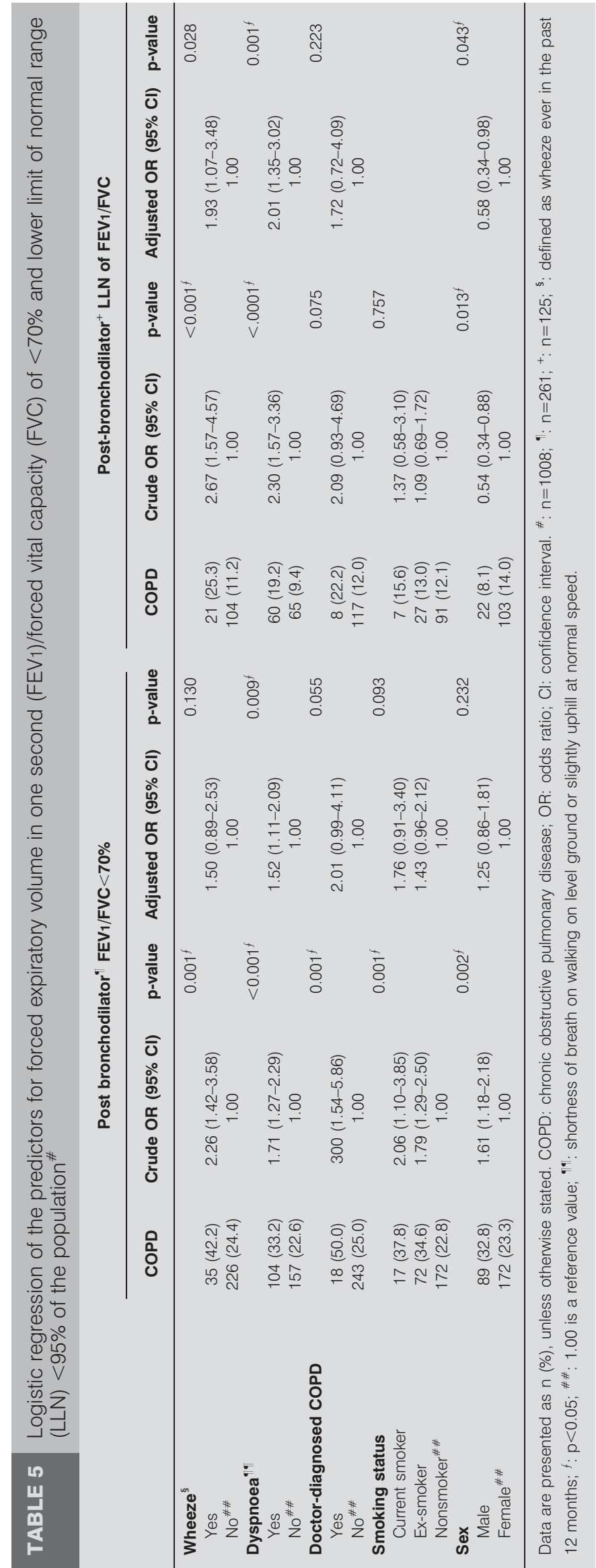

not available. In the present elderly Chinese population, the GOLD definition led to an unacceptable over-estimation of the prevalence of airflow obstruction that far exceeded (two times) that based on a more physiological parameter, such as the LLN. Such a difference has been reported in the Caucasian population before [15-17] and thus it appears that this observation is exactly the same for the other ethnicities. The positive association between symptoms of the elderly and the functional definitions has also supported this idea of using the more physiological LLN definition. In addition, the current study has found a high prevalence of COPD among the nonsmokers $(22.8 \%$ by the $\mathrm{FEV} 1 / \mathrm{FVC}$ ratio of $<70 \%$ versus $12.1 \%$ by LLN of the FEV1/FVC ratio).

There have been several major COPD prevalence studies based on spirometry in recent years [18-20]. All these studies used the definition of post-bronchodilator $\mathrm{FEV} 1 / \mathrm{FVC}$ ratio of $<70 \%$ for COPD and surveyed subjects aged $\geqslant 40$ yrs. Few studies have compared FEV1/FVC ratio of $<70 \%$ with LLN of the FEV1/FVC ratio for the assessment of airflow obstructions. A retrospective study, using the consecutive spirometry tests from clinic/hospital based subjects in the USA [15], found that when comparing the LLN method versus the $<70 \%$ fixed ratio method, the former could identify $\sim 7 \%$ less in the prevalence of airflow obstruction depending on the different reference equations used, whereas age was the strongest predictor of discordance. The USA study was, however, limited by using pre-bronchodilator instead of post-bronchodilator values, in addition to its retrospective study design. A prospective community study in New Zealand has the merit of using both post-bronchodilator FEV1/FVC fixed ratio of $<70 \%$ and LLN of the FEV1/FVC ratio for the diagnosis of COPD [16]. The New Zealand study involved 749 subjects aged $\geqslant 40$ yrs and found that the GOLD-defined, age-adjusted prevalence $(95 \%$ CI) was $14.2 \%$ (11.0-17.0) compared with a LLN-defined, ageadjusted, post-bronchodilator prevalence of 9.0\% (6.7-11.3) in the same cohort [16]. Only $38.9 \%$ of the subjects in that study were aged $\geqslant 60$ yrs and this probably accounted for the lower rate of COPD using both definitions [16] when compared with the present study.

It is still uncertain what the best definition is for the purpose of diagnosing COPD. As shown by the current study and others, FEV1/FVC fixed ratio of $<70 \%$ consistently diagnosed more COPD than using the LLN definition, particularly for the elderly $[15,16,21]$. In a study that involved the measurement of spirometry in 71 healthy, elderly never-smokers, it was found that $35 \%$ of the asymptomatic subjects would be classified as having at least stage one COPD using the GOLD definition of FEV1/FVC fixed ratio of $<70 \%$ [17]. It appears that using this definition would result in over-diagnosis of COPD. However, in a recent study of 4,965 subjects aged $\geqslant 65$ yrs that aimed to determine the morbidity and mortality among those with an FEV1/FVC ratio of $<0.7$ but above the LLN, it was found that subjects with such lung function had an increased adjusted risk of death and COPD-related hospitalisation during follow-up when compared with asymptomatic individuals with normal lung function (i.e. FEV1/FVC ratio of $>70 \%$ ) [22]. Furthermore, persons with FEV1 $<80 \%$ pred normal showed an increased adjusted risk of death and COPD related hospitalisation (regardless of the FEV1/FVC ratio). Patients with an FEV1 $>80 \%$ pred, but a FEV1/FVC ratio 
between 0.7 and LLN, did not show an increase in adjusted risk of death after adjusting for age and sex. Although their study was limited by lack of post-bronchodilator values, it was suggested that a fixed FEV1/FVC ratio of $<70 \%$ might still identify at-risk patients.

The current study noted a high prevalence of COPD based on both definitions among the life-long nonsmokers. Previous studies have shown that passive smoking and biomass exposure were associated with COPD in nonsmokers [23, 24]. The fact that about half of the present subjects had passive smoking exposure whereas $>70 \%$ had exposure to combustion emissions from biomass might explain the high prevalence of airflow obstruction in the nonsmokers. However, the current logistic regression analysis, failed to show a statistically significant association between the exposure to passive smoking/biomass and COPD. This could be due to the relatively small sample size and the fact that the majority of females in the present study population had exposure to biomass during cooking when they were young. The present authors learnt from these elderly subjects that before World War II, they cooked by burning firewood and grass. After the war, they used kerosene as the cooking fuel, and from the mid 1970s to early 1980s, they switched to natural gas. The subjects in the current study had similar percentages of smokers and ex-smokers when compared with the general population at similar age groups according to the Hong Kong Census and Statistics Department data [25].

In a major study of 20,245 participants using questionnaires and spirometry in mainland China, the prevalence of COPD (defined by FEV1/FVC ratio of $<70 \%$ ) was significantly higher in: rural residents; elderly patients; smokers; in those with lower BMI; less education and poor ventilation in the kitchen; those who were exposed to occupational dusts or biomass fuels; and in those with pulmonary problems in childhood and a family history of pulmonary diseases [20]. However, no relationship between education and airflow obstruction using both definitions was found in the present study. The discrepancies in observation may be related to the differences in sample size and study populations.

One major limitation of the current study is the potential selection bias. The elderly subjects were chosen from the community centres and it is possible that those with more symptoms would join the study. Moreover, there were more females than males, although this is the characteristic in the elderly centres nowadays. There is a possibility of misclassifying some cases with asthma and other diseases as COPD since detailed medical assessment was not performed on these subjects and a chest radiograph was not included in the protocol.

In summary, while the Global Initiative for Chronic Obstructive Lung Disease guidelines have currently recommended the fixed ratio of forced expiratory volume in one second/forced vital capacity of $<70 \%$ for the diagnosis of chronic obstructive lung disease, regardless of patient age, in order to simplify the diagnostic definition, the present authors have shown that such a definition would diagnose many more chronic obstructive lung disease cases than the lower limit of normal range definition in the current elderly population. However, as the subjects in the present study were mostly females, with a low educational level and previous exposure to biomass during formative years, direct extrapolation of the results to the general patient population in western countries is not possible. It cannot be confirmed that the lower limit of normal range will give a "better" definition for airflow obstruction in terms of balance between specificity and sensitivity (and predictive values). Longitudinal studies, with serial examination of lung function, symptoms and physician's assessment will provide more information as to which is the more appropriate spirometric definition for the diagnosis of chronic obstructive pulmonary disease.

\section{ACKNOWLEDGEMENTS}

The present authors would like to thank H.Y. Chu, C. Ho and D. Chan for helping with the field study; and K. Lai and H.Y. Chu (all Dept of Medicine and Therapeutics, The Chinese University of Hong Kong, Shatin, Hong Kong) for helping with the statistical analysis.

\section{REFERENCES}

1 Lopez AD, Mathers CD, Ezzati M, Jamison DT, Murray CJL. Global Burden of Disease and Risk Factors. Washington, The World Bank, 2006.

2 Lopez AD, Shibuya K, Rao C, et al. Chronic obstructive pulmonary disease: current burden and future projections. Eur Respir J 2006; 27: 397-412.

3 Ko FW, Lai CK, Woo J, et al. 12-year change in prevalence of respiratory symptoms in elderly Chinese living in Hong Kong. Respir Med 2006; 100: 1598-1607.

4 Global Initiative for Chronic Obstructive Lung Disease. Global Strategy for the Diagnosis, Management and Prevention of Chronic Obstructive Pulmonary Disease. NHBLI/WHO Workshop Report. Reviewed edition. 2006. www.goldcopd.com/Guidelineitem.asp? $11=2 \& 12=1 \&$ intId $=996$ Date last accessed: July 14, 2008. Date last updated: 2006.

5 Hankinson JL, Odencrantz JR, Fedan KB. Spirometric reference values from a sample of the general U.S. population. Am J Respir Crit Care Med 1999; 159: 179-187.

6 Enright PL, Kronmal RA, Higgins M, Schenker M, Haponik EF. Spirometry reference values for women and men 65 to 85 years of age. Cardiovascular health study. Am Rev Respir Dis 1993; 147: 125-133.

7 Quanjer PH, Tammeling GJ, Cotes JE, Pedersen OF, Peslin R, Yernault JC. Lung volumes and forced ventilatory flows. Report Working Party Standardization of Lung Function Tests, European Community for Steel and Coal. Official Statement of the European Respiratory Society. Eur Respir J 1993; 6: Suppl. 16, 5-40.

8 Crapo RO, Morris AH, Gardner RM. Reference spirometric values using techniques and equipment that meet ATS recommendations. Am Rev Respir Dis 1981; 123: 659-664.

9 American Thoracic Society, Lung function testing: selection of reference values and interpretative strategies. Am Rev Respir Dis 1991; 144: 1202-1218.

10 Pellegrino R, Viegi G, Brusasco V, et al. Interpretative strategies for lung function tests. Eur Respir J 2005; 26: 948-968.

11 Ferris BG. Recommended respiratory disease questionnaire for use with adults and children in epidemiology research. Am Rev Respir Dis 1978; 118: 7-53. 
12 Ip MS, Ko FW, Lau AC, et al. Updated spirometric reference values for adult Chinese in Hong Kong and implications on clinical utilization. Chest 2006; 129: 384-392.

13 Leung SS, Lau JT, Xu YY, et al. Secular changes in standing height, sitting height and sexual maturation of Chinese-the Hong Kong Growth Study, 1993. Ann Hum Biol 1996; 23: 297-306.

14 Miller MR, Hankinson J, Brusasco V, et al. Standardisation of spirometry. Eur Respir J 2005; 26: 319-338.

15 Roberts SD, Farber MO, Knox KS, et al. FEV1/FVC ratio of $70 \%$ misclassifies patients with obstruction at the extremes of age. Chest 2006; 130: 200-206.

16 Shirtcliffe P, Weatherall M, Marsh S, et al. COPD prevalence in a random population survey: a matter of definition. Eur Respir J 2007; 30: 232-239.

17 Hardie JA, Buist AS, Vollmer WM, Ellingsen I, Bakke PS, Morkve O. Risk of over-diagnosis of COPD in asymptomatic elderly never-smokers. Eur Respir J 2002; 20: 1117-1122.

18 Buist AS, McBurnie MA, Vollmer WM, et al. International variation in the prevalence of COPD (the BOLD Study): a population-based prevalence study. Lancet 2007; 370: 741-750.

19 Menezes AM, Perez-Padilla R, Jardim JR, et al. Chronic obstructive pulmonary disease in five Latin American cities (the PLATINO study): a prevalence study. Lancet 2005; 366: 1875-1881.

20 Zhong N, Wang C, Yao W, et al. Prevalence of chronic obstructive pulmonary disease in China: a large, population-based survey. Am J Respir Crit Care Med 2007; 176: 753-760.

21 Lau AC, Ip MS, Lai CK, et al. Variability of the prevalence of undiagnosed airflow obstruction in smokers using different diagnostic criteria. Chest 2008; 133: 42-48.

22 Mannino DM, Sonia Buist A, Vollmer WM. Chronic obstructive pulmonary disease in the older adult: what defines abnormal lung function? Thorax 2007; 62: 237-241.

23 Liu S, Zhou Y, Wang X, et al. Biomass fuels are the probable risk factor for chronic obstructive pulmonary disease in rural South China. Thorax 2007; 62: 889-897.

24 Yin P, Jiang CQ, Cheng KK, et al. Passive smoking exposure and risk of COPD among adults in China: the Guangzhou Biobank Cohort Study. Lancet 2007; 370: 751-757.

25 Hong Kong Statistics and Census Department. Pattern of smoking. www.censtatd.gov.hk/freedownload.jsp?file= publication/feature_article/B70612FB2006XXXXB0100.pdf\& title $=$ Pattern + of + Smoking $+($ Released + on $+20 \% 2$ f12\%2f2006) \&issue $=-\&$ lang $=1 \& c=1$ Date last accessed: July 5, 2008. Date last updated: July 5, 2008. 